\title{
Transterritórios: campo da arte e internet
}

\section{Resumo}

Abordagem do campo da arte como um lugar de trabalho imaterial, onde se constrói o valor arte. Análise das relações entre esse espaço e o ciberespaço, considerando suas interconexões e a construção de um transterritório. 


\begin{abstract}
This article approaches the artistic field as a place of immaterial work, and where art's value is built by society. It analyses the interconnections between such place and the cyberspace, and looks into the conceptual construction of a trans-territory.
\end{abstract}


O circuito globalizado da arte contemporânea distribui-se por bienais e grandes mostras que, em nível mundial, atraem um público específico de especialistas (artistas, curadores, críticos, colecionadores e marchands) que circula acompanhando esses eventos. Cada um deles tem a função de construir um ponto de fusão e tensão entre esse circuito internacional e os públicos locais. Assim, o lugar da arte não é algo que existe em si, ele é uma tarefa, uma territorialidade construída, em que pontos de convergência e uma consciência de pertinência se criam, e as fronteiras não são somente limites e separações, são também espaços de trocas, articulações e permeações.

Os deslocamentos e a desterritorialização caracterizam esse mundo contemporâneo, marcado pela ação das mídias internacionalizadas, reforçadas pelo consumo que uniformiza padrões de comportamento e valores. Acrescentou-se a essa mobilidade dos territórios físicos geográficos, a partir da segunda metade dos anos 9o, a dinâmica do ciberespaço, que gradativamente se expande ocupando diferentes instâncias da sociedade. Nele, estabelecem-se novas possibilidades relacionais. $\mathrm{O}$ internauta pode, de forma solitária, percorrer as inúmeras vias à sua disposição, buscando encontrar os objetos de seu interesse e se conectar com seu grupo ou tribo. Nessa rede de identidade de interesses, o indivíduo passa a compartilhar experiências e informações. A arte detém, nesse amplo e difuso conjunto de infovias, os seus lugares particulares, que determinam as suas relações de pertencimento. Assim, cada vez mais instituições e artistas vêm buscando ampliar a abrangência de seu trabalho, fazendo voos experimentais, com o uso da internet, para a difusão de suas práticas e produtos. Eles objetivam com isso aceder ao público dentro da tela de seu computador, ampliando seu leque de relações além de seu espaço físico geográfico específico. Cresce e diversifica-se continuamente a presença da arte na rede web, deixando perceber-se que uma nova realidade se instala no seu circuito tradicional. Como pensar, então, a institucionalização da arte contemporânea, a crítica de arte, os museus, as bienais e o mercado de arte desconsiderando esse novo fenômeno?

\section{Lugares da arte, ou a arte como lugar?}

A maioria dos autores nos âmbitos da Sociologia e da Economia evidenciam hoje o desenvolvimento do que denominam capitalismo cognitivo ou cultural. Segundo eles, o capitalismo clássico fabrica objetos de onde extrai a mais-valia ou lucro. O capitalis- 
1. O conceito de trabalho imaterial é desenvolvido por Maurizio

Lazzarato. Algumas de suas ideias são apresentadas em http://revistaglobal.wordpress. com/2006/12/17/lazzarato-eentrevistado-pela-carta-maior/

2. Obra de Joseph Kosuth denominada Uma e Três Cadeiras, exposta no MOMA de Nova Iorque, em 1965.

3. O trabalho de Giorgio Vasari, no reconhecimento social da categoria artística, e na valorização de seus mecenas, foi primorosamente analisado por Georges Didi Huberman em seu livro Devant L'Image, publicado em 1990, em Paris, pela editora Minuit. Também Carlo Ginzburg em seu texto clássico História da Arte Italiana, publicado no livro A Micro-História e Outros Ensaios, Lisboa/ R.J. , Difel/ Betrand Brasil, 1991, enfatiza a importância de Giorgio Vasari na consolidação de um padrão hegemônico de arte. mo cultural produz desejos, crenças e valores, o lucro é gerado mais no marketing de um produto do que em sua produção fabril.

Nesse novo modelo capitalista, o elemento chave é o trabalho imaterial $^{1}$, que cria e modifica o ambiente ideológico e cultural do consumidor, produzindo uma relação social que transforma o usuário. Para entender-se isso, deve-se levar em conta que o capitalismo clássico produz objetos e obtém seu lucro na sua comercialização; no capitalismo cognitivo ou cultural, que se desenvolveu nas últimas décadas, é a fabricação de desejos e crenças que gera a maior riqueza. Assim, o valor de um tênis encontra-se mais no trabalho intelectual que elabora o conjunto de idéias que garante que ele representa um estilo de vida do que na sua produção fabril. A fábrica produz objetos, a empresa produz um mundo. A mercadoria produzida pelo trabalho intelectual não se acaba no consumo, mas se alarga e transforma o ambiente ideológico e cultural do consumidor.

O campo da arte pode ser considerado um antecessor desse capitalismo cultural e do trabalho imaterial, pois é nele que se cria o valor arte e todo o conjunto de ideias e crenças que a sustentam. A problemática desse valor pode ser abordada de inúmeros ângulos. Entretanto, é preciso destacar-se que a arte é, por si própria, uma categoria social instauradora de conceitos e padrões. Isso porque, de um imenso conjunto das práticas simbólicas plásticas que envolvem todo tipo de manifestação, - desde uma blusa pintada vendida em uma feira de artesanato, passando pela pintura corporal e pelo grafite, até uma cadeira com sua foto e o texto de sua definição no dicionário $^{2}$ - , somente uma pequena parcela recebe a definição, o valor de arte e o reconhecimento coletivo dele decorrente. Nesse reconhecimento, as instituições do campo artístico desempenham um importante papel. Elas constituem o lugar oficial onde passa tudo que é produzido como arte, difundido como arte, comentado como arte e vendido como arte.

Resultante de um trabalho imaterial, essa categoria de produção é bastante recente na história da humanidade, tendo surgido como resultado de um status quo que determinados produtores obtiveram no Renascimento. Os pressupostos desse grupo restrito de criadores, bem como suas conexões com a elite econômica, política e cultural que os mantinha, nesse caso, foram brilhantemente defendidos por Giorgio Vasari, na obra Vida de Homens Ilustres ${ }^{3}$. Considerado como possivelmente o primeiro crítico de arte, ele marcou o surgimento desse conjunto de relações socialmente reconhecido. 
Entretanto, foi percorrido um largo caminho no estabelecimento de seus estatutos institucionais, com a instauração das academias e dos museus de belas artes (na Itália, em 1585, na França, em 1648). Somente na segunda metade do século XVIII, foram formuladas suas estruturas teóricas, com a criação das disciplinas de Estética, por Alexander Baumgarten (1714-1762), e História da Arte, por Johann Winkelman (1717-1768), e da atividade de Crítica de Arte, por Denis Diderot $(1713-1784)^{4}$.

Com essa rede de relações, estabeleceu-se o sistema da arte, qual seja: “... o conjunto de indivíduos e instituições que produzem, difundem e consomem objetos e eventos por eles mesmos definidos como artísticos e determinam os critérios da Arte para toda uma sociedade em determinada época". ${ }^{5}$ Essa categorização estabelece padrões de classificação superiores para as obras de arte, definindo como artesanato ou artes menores as demais produções que ficam fora desse sistema. Assim, pode-se afirmar que arte é um atributo que instaura o valor de determinados objetos ou eventos e que o mesmo é arbitrado através de um sistema de instituições e indivíduos.

Isso não éalgo estabelecido aprioristicamente, pelo contrário, constrói-se historicamente, modificando-se em consequência de lutas internas que se desenvolvem articuladas às necessidades da sociedade em que se inserem. As disputas pelo poder simbólico envolvem valores estéticos, mas também interesses políticos, econômicos e sociais. Segundo Pierre Bourdieu, os indivíduos que estão estabelecidos no sistema lutam para garantir seus privilégios e o valor de seu capital cultural. Os que estão fora lutam para entrar e também para alterar os mecanismos de valoração simbólica (BOURDIEU, 1990). Dessas lutas estéticas e políticas, decorreram as transformações que levaram à passagem do sistema acadêmico ao sistema moderno e, que atualmente estabelecem o sistema contemporâneo. Essa sequência de mudanças, porém, não pressupõe o desaparecimento consecutivo de cada um dos sistemas anteriores. Embora os novos passem a deter certa hegemonia, vestígios dos demais persistem. Além disso, também há disputa entre os interesses locais, nacionais e internacionais -- permeados pelas relações de poder entre centro e periferia --, em uma luta pela dominação simbólica, que faz parte de uma gama de diferentes poderes.

As práticas de artistas, críticos, curadores, marchands, colecionadores e outros tantos envolvidos no sistema da arte podem ser consideradas um trabalho imaterial, uma vez que o valor se instaura não
4. Paul Kristeler analisa esse processo de estabelecimento de sistemas teóricos no seu livro El Pensamiento Renascentista y las Artes, Madrid, Taurus, 1986.

5. Esse conceito foi desenvolvidoem BULHÕES, Maria Amélia. Participação e distinção: o sistema das artes no Brasil nas décadas de 6o e 7o. Tese de Doutorado, USP, 1990. 
nos objetos em si mas no conjunto de idéias, desejos e crenças que a arte estabelece. É o trabalho desses indivíduos que cria e transforma o ambiente ideológico dos participantes, que consomem, muito mais do que objetos, uma relação social de pertencimento. Assim, o capitalismo cognitivo -- que se organiza em redes e fluxos -- no campo da arte, cria e transforma o ambiente, produz um mundo, fabrica crenças. A própria História da Arte deve ser percebida como uma construção que identifica e consagra artistas e obras, incorporando progressivamente manifestações mais contemporâneas e atuando, ainda, como referencial para definições de valor em relação às novas produções.

\section{Transterritórios ou campos de cruzamentos}

A arte contemporânea veio instaurar novas relações no sistema da arte, com o deslocamento do foco do objeto para o evento, tornando, assim, a exposição o lugar da escritura da História da Arte e o curador a figura central no sistema. A difusão pode ser considerada como um dos seus mais importantes aspectos, produzindo-se nela os valores estéticos, ideológicos e econômicos da arte.

Uma das mudanças relacionadas à sua difusão e à sua recepção diz respeito ao fato de a arte ter se transformado em uma das principais esferas de construção de identidade. A atividade artística, hoje, não é mais encarada somente como status, lazer ou prazer estético, seu crescimento e sua proliferação devem ser considerados como importante agente da modernização em uma nova etapa da sociedade de consumo. Alterações na esfera da produção artística estão relacionadas com os novos direcionamentos de sua função no âmbito de sua difusão, criando espaços que possibilitam trazer à tona pro-

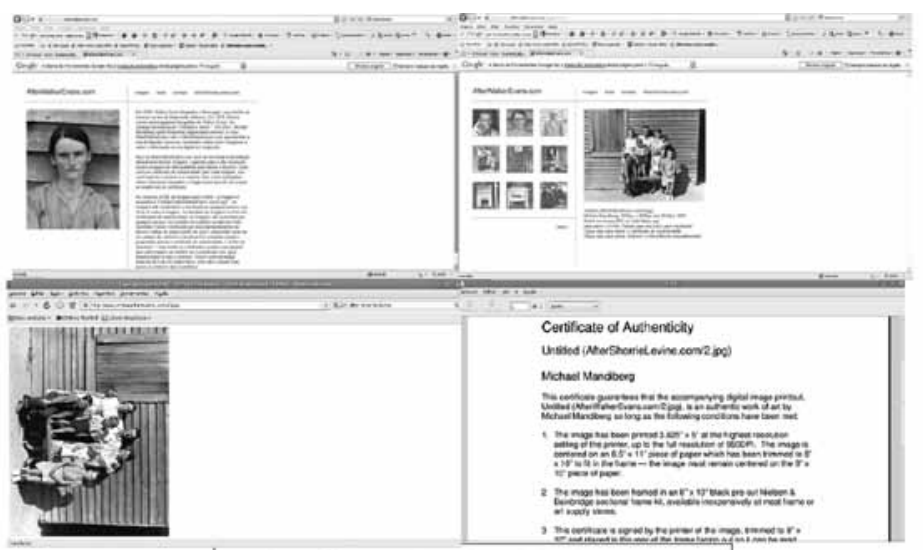


blemáticas importantes do mundo contemporâneo de ordem tanto local como global, abordando questões muito diversas que abarcam a esfera pública e o domínio das individualidades.

O desenvolvimento dos processos comunicacionais no mundoatual e a desterritorialização da indústria cultural são importantes fatores que influenciam a expansão sem precedentes do universo da arte que se vivencia atualmente e que termina por transformar este em um dos principais setores da economia na sociedade globalizada. Essa mudança qualitativa e quantitativa implicou alterações que trouxeram significativas redefinições ao papel da arte num contexto social marcado por um crescimento acelerado da população e pela mundialização da cultura.

O contemporâneo repousa essencialmente sobre a experimentação de todo tipo de ruptura e transgressão dos critérios artísticos e dos quadros disciplinares e mesmo morais e jurídicos. O valor da obra não reside mais no objeto,mas no conjunto de mediações que ele autoriza entre o artista e o espectador, tais como descrições de fabricação da obra, legendas biográficas, traços da execução, redes relacionais, escala de interpretações, e paredes de museus são solicitadas a integrar os objetos que as violentam. O sistema da arte contemporânea é um espaço internacionalizado, gerido pelas redes de galerias e de instituições, em que a participação destas últimas se evidencia preponderante, mas as fronteiras desse espaço têm se mostrado cada vez mais fluídas, com inúmeras e diferenciadas produções circulando em seu interior.

É no quadro dessa contemporaneidade que as relações da internet com a arte devem ser pensadas, uma vez que a própria rede $w e b^{6}$ é recente, e sua difusão internacional junto ao grande público data da segunda metade dos anos 9o. A ação da arte nessa rede de comunicação, mesmo assim, já tem sua história relatada ${ }^{7}$ e muito material publicado on-line com inúmeras listas de discussão. A leitura dessa fortuna crítica permite observar que, em um primeiro momento, se instaurou uma espécie de deslumbramento com esse meio e suas ferramentas, os quais, de certa forma, respondiam a algumas expectativas de participação e interatividade das vanguardas dos anos 70. Experimentos feitos com fax, telefone e outras redes de criação foram alguns dos seus antecessores no campo da arte. Posteriormente, houve uma certa desilusão em relação às possibilidades revolucionárias do meio e a consciência de estruturas de poder e controle por parte dos grandes monopólios econômicos e dos sistemas de governo.
6. Oespaço de comunicações utilizando a internet é um conglomerado de redes interligadas pelo protocolo IP, a world wide web (www), comumente denominada web.

7. Uma obra fundamental na escrita dessa história é GREENE Rachel, Internet Art, Thames EHudson, Londres, 2005. 
8. Site é um conjunto de documentos interligados entre si que partilham o mesmo nome de domínio; uma página da internet, espaço adquirido em provedores com mais capacidade de armazenamento e possibilidades gerenciais e técnicas.

Plataformas são processos operacionais para gerir os espaços. O termo também identifica espaços a serem utilizados e administrados em áreas conjuntas, com amplas possibilidades de gerenciamento e com diferenciados programas.
Retomando a premissa de que arte é uma categoria histórica que instaura valor e de que este é arbitrado através do sistema da arte, como é possível se abordarem os cruzamentos que se realizam entre arte e internet nas atividades de difusão, reconhecimento e valoração?

Para se identificarem os lugares da arte no ciberespaço, é necessário explorarem-se inúmeros blogs, sites e, plataformas ${ }^{8}$, estabelecendo alguns ordenamentos que permitem perceber como esses lugares se estruturam, como desenvolvem seus métodos e processos, como definem seus objetivos e como se conectam ao mundo tradicional da arte. Uma importante diferenciação básica se impõe entre dois modos de existência física dos diversos lugares de arte estabelecidos na rede. Por modo de existência física, entende-se sua estruturação na rede e fora dela, ou seja, sua realidade particular em termos territoriais. Um primeiro grupo abrange as instituições que existem fisicamente em um determinado local geográfico, sendo seu espaço on-line um veículo de divulgação dos projetos que desenvolve no âmbito do circuito tradicional da arte. Esse é o caso dos sites de museus, como o Louvre ou a Tate Galery, que divulgam as exposições que estão realizando, seus acervos e outros diferentes elementos de seu funcionamento. Revistas como Flash e Art Dialy, em suas edições na internet, apresentam imagens das publicações, informando os artigos publicados, números antigos e resenhas. Eventos como Arte Cidade e Percursos mostram em mapas os locais onde ocorrem as intervenções dos artistas, assim como disponibilizam imagens das obras produzidas e instaladas. A maioria das feiras de arte divulga em seus sites a lista das galerias e os artistas participantes, as atividades paralelas, bem como suas program-

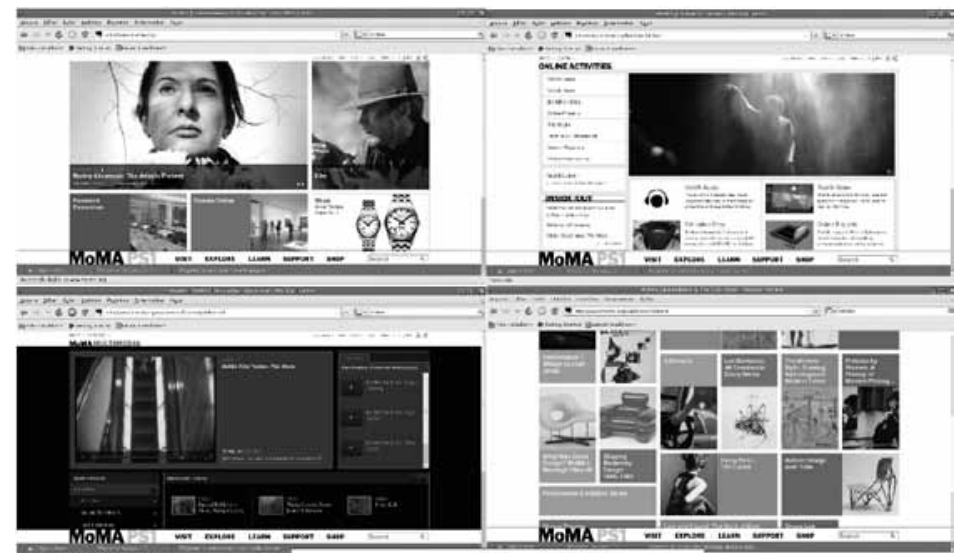




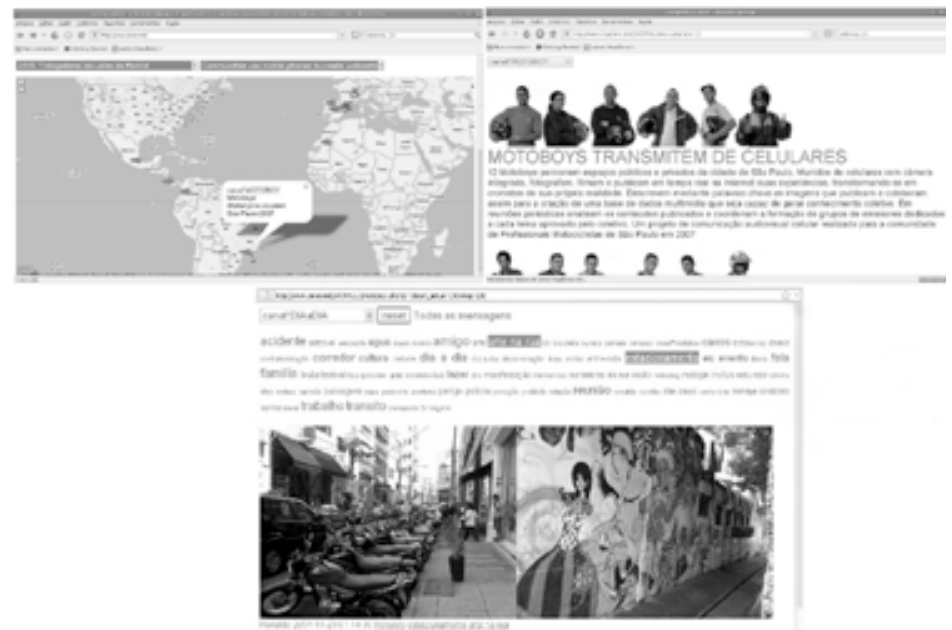

$<$ http://www.zexe.net><http://www.megafone.net/SAOPAULO> Antoni Abad, Eugenio Tisselli,

ações. Em termos tecnológicos, em geral, esses espaços utilizam processos de digitalização para colocar seus conteúdos na rede, e seu objetivo é ampliar suas possibilidades de divulgação, transpondo informações de suas atuações para o ciberespaço. Mesmo que possibilitem interações e algum tipo de participação do usuário, via de regra, funcionam como uma espécie de portfólio de imagens e textos. Esses lugares na rede buscam contato com um público mais amplo e uma abrangência internacional que seria difícil obter sem o uso da internet.

Um segundo grupo reune os espaços que não existem fisicamente em nenhum determinado local geográfico. Tendo sidos criados especificamente para a internet, não detêm uma existência física fora da rede, limitando-se a tudo que disponibilizam on-line. Suas estruturas e seus conteúdos são quase sempre pensados e produzidos a partir das possibilidades oferecidas pelas novas ferramentas de linguagem digital e com os recursos tecnológicos das interfaces de perfil interativo autogerativas. Nesse segundo grupo, encontram-se, por exemplo, o Museun Uruguay of Visual Arts (MUVA) e o Geenmuseun, museus cujos acervos são constituídos de obras que existem em diferentes locais, mas que, como conjunto, se apresentam somente no espaço virtual da rede. Eles oferecem aos usuários da internet exposições a que jamais teriam acesso fora dela, desenvolvendo, com sua prática, o conceito do museu imaginário de André Malraux. Esses museus identificam se com um processo 
de substituição simbólica e contribuem para a problematização do sentido da arte na sociedade contemporânea. Também se enquadram nesse segundo grupo as revistas on-line como Flux, It's Liquid e Art Web Brasil, que divulgam os mais diversos assuntos sobre arte com artigos, imagens e notícias. Elas incrementam a participação dos usuários oferecendo leitura a um público mais amplo que o seu tradicional, pois, geralmente, são revistas de pouca circulação e alto custo. Os espaços de conexão e os net lab são igualmente lugares de arte cuja existência se restringe à internet; tendo sido criados especificamente a partir das necessidades e dos interesses desse novo tipo de produção. Eles se dedicam diretamente a interconectar esse tipo de trabalho, funcionando só a partir das possibilidades oferecidas pelos recursos tecnológicos da rede. Essas organizações são como plataformas, hospedando trabalhos de arte produzidos a partir de experimentos com softwares, interligando e difundindo reflexões, como é o caso de Art Info, Turbulance e Rhizome. Há ainda, os sites de eventos, como Treasurecrumbs, criados especialmente para abrigar projetos de net arte, legitimando e difundindo essa produção.

Pode-se observar como no ciberespaço diferentes interesses atuam de forma complexa na constituição do que se reconhece como arte, não se restringindo, portanto, somente às instâncias oficiais do sistema cultural. Percebem-se também, nessa rede de arte, o cruzamento de diferentes pontos de vista e a coexistência de correntes e interesses bem diversificados. Isso leva a pensar o ciberespaço como uma economia de negociação das diferenças. Nesse lugar virtual, tudo se torna mais facilmente permeável, os choques de opiniões se dispersam, e a ausência da proximidade física esfria as disputas mais acirradas e emocionais. Esse trânsito de fluxos pode funcionar como gestão de posicionamentos antagônicos conectados, tais como, local versus global, individual versus coletivo, ou contemplativo versus interativo, moderno versus contemporâneo.

A internet é um meio com características específicas que pode servir ao sistema da arte em termos de divulgação, produção em rede e mesmo no de criação de obras com os recursos e as ferramentas próprias do meio. Por sua característica multimídia, ela abre diversas possibilidades expressivas. A interatividade do meio oportuniza a socialização da produção estética segundo os ideais de Brian Hols. A produção e a distribuição em rede amplia as possibilidades comunicacionais e a produção de comunidades.

Contemporaneamente, a desterritorialização impõe-se como processo cultural em escala mundial, no qual o mercado e a im- 
prensa de arte propõem um mundo sem território, onde todos os signos se misturam e acabam por parecer um único, no interior do qual fica difícil se reconhecerem as diferenças.

Entende-se a transterritorialidade como um processo de construções simbólicas particulares, tendo em vista assinalar peculiaridades individuais e de grupos. Propõe-se pensar a transterritorialidade no mundo virtual da internet como forma de construir relações com territórios geográficos específicos, laços de identidade, novos olhares e redes de comunicação. Ela pode representar na arte contemporânea, formas de estabelecer diferenças frente aos processos de homogeneização que se verificam em âmbito mundial, ampliando o debate dentro dos movimentos de internacionalização e mundialização da cultura, com ênfase em questões referentes às artes visuais. Ela apresenta, ainda, agenciamentos críticos, através de práticas de produção de visualidade que reclamam a dissolução das fronteiras hierárquicas da arte. Por fim, favorece a criação de formas de subjetivação que oportunizam ao seu receptor subjetivação e produção de identidade e a crítica permanente dos modos e instrumentos de politização do espaço da visualidade, realizando experiências de socialização e produção de comunidade.

\section{MARIA AMÉLIA BULHÕES}

É pesquisadora sênior do CNPq, professora e orientadora do Programa de Pós-Graduação em Artes Visuais da UFRGS, com pós-doutorado nas Universidades de Paris I, Sorbonne, e Politécnica de Valencia. Atua como crítica de arte, dirige o www.ig.art.br, organizou e publicou diversos livros, colaborando regularmente com artigos em revistas nacionais e internacionais.

E-mail: mariameliabu@gmail.com 